\title{
A study of effect of oral PGE1 and cervical PGE2 on induction of labor and mode of delivery
}

\author{
Sukanya Mukherjee ${ }^{1}$, H. Valson ${ }^{1 *}$, Balaji K. ${ }^{2}$
}

\begin{abstract}
${ }^{1}$ Department of Obstetrics and Gynecology, ${ }^{2}$ Department of Biochemistry, D. M. Wayanad Institute of Medical Sciences, Naseera Nagar, Meppadi, Wayanad, Kerala, India
\end{abstract}

Received: 19 April 2018

Accepted: 24 April 2018

\section{*Correspondence:}

Dr. H. Valson,

E-mail: h.valson@gmail.com

Copyright: () the author(s), publisher and licensee Medip Academy. This is an open-access article distributed under the terms of the Creative Commons Attribution Non-Commercial License, which permits unrestricted non-commercial use, distribution, and reproduction in any medium, provided the original work is properly cited.

\begin{abstract}
Background: Induction of labor is one of the most important procedures done by the Obstetricians. Induction of labor with the help of prostaglandins offer the advantage of promoting cervical ripening along with stimulating the contractility of the myometrium.

Methods: 200 pregnant women with singleton pregnancy both nulliparous and multiparous, were included in the study at term gestation ( $>39$ weeks) with Bishop's score $<6$, and reactive NST. The subjects were divided in to two groups Group A including patients who were given oral PGE1 - $50 \mathrm{mcg}$ Tab, and Group B with cervical PGE2, 0.5 $\mathrm{mg}$, gel. The outcome indicators were recorded in both Group A and Group B and analyzed. The mean time taken from induction to vaginal delivery in Group A was $628 \pm 67$ minutes and in Group B was $839 \pm 118$ minutes. Incidence of LSCS in Group B when compared to Group A (p value <0.005).

Results: Incidence of LSCS in Primi's in Group B compared to Primi's in Group A was statistically significant (p value 0.009). Non-progression of labor was observed to be the major indication for LSCS in Group B. Meconium stained labor was found to be the major indication for LSCS in Group A.

Conclusions: The study concludes that using $50 \mathrm{mcg}$ oral misoprostol, is an effective and safe mode of induction of labor in comparison to PGE2 gel. Vaginal deliveries are more with the use of oral misoprostol and the induction to delivery interval is also lesser than that in cervical PGE2 use.
\end{abstract}

Keywords: Induction, Labor, Prostaglandin

\section{INTRODUCTION}

Induction of labor is one of the most important procedures done by the Obstetricians. The Incidence of induction across different settings varies from 5 to $22 \%$ of all labor room admissions. ${ }^{1-3}$ Induced labor is artificial stimulation of uterine contractions before the onset of labor, any time after the fetus attains viability with the main aim to achieve vaginal birth. ${ }^{4}$ Pharmacological modes of induction of labor include prostaglandins (per oral or intra-vaginal or intra-cervical) and oxytocin .Successful induction of labor is related to the condition or state of the cervix. ${ }^{5}$ The common indications for induction are post-dated pregnancy, PROM, and elective inductions. $^{4}$ Induction of labor with the help of prostaglandins offer the advantage of promoting cervical ripening along with stimulating the contractility of the myometrium. ${ }^{1-3}$ The indications for Induction has increased so much in modern obstetrics to avoid the slightest risk to baby or mother that we are electively inducing labor at 39 weeks of pregnancy; though we know that induction is carried out routinely in postdated pregnancies. Many studies have indicated that about $10 \%$ of pregnancies remain undelivered beyond 42 weeks, so timely induction remains an important statement to bring out better labor outcomes in both baby and mother. ${ }^{6}$ The 
work embodied here aims to study the effect of oral PGE1 and cervical PGE2 on induction of labor and the outcomes such as Induction to delivery interval, Incidence of vaginal delivery, Incidence of emergency LSCS and indications for LSCS.

\section{METHODS}

200 pregnant women with singleton pregnancy both nulliparous and multiparous, were included in the study at term gestation ( $>39$ weeks) with Bishop's score $<6$ and reactive NST. The study population was selected from the patients who came for safe confinement from the period of August 2015 to August 2016, at DM WIMS Medical college hospital, Wayanad. All women included in the study were above 18 years and less than or equal to 35 years of age. Women with previous history of LSCS, history of uterine surgery, bad obstetrics history, multiple gestation, non-reassuring fetal heart rate, all high risk pregnancies, patients with CPD, patients with known contra indications to prostaglandins, PROM and Placenta Previa were excluded from the study. All participants included in the study were selected for induction as per the institution induction protocol and had given an informed written consent after they were explained about the objective of the study (induction consent). A bimanual pelvic examination was done for assessment of cervical Bishop's score. NST was done to ensure the fetal wellbeing on admission and an hour before application of prostaglandin.

The subjects were divided in to two groups Group A $(n=100)$ and Group B $(n=100)$. All women were admitted in labor ward, after an NST were induced as following,

Group A included patients who were given oral PGE1 $50 \mathrm{mcg}$ Tab, doses repeated once every 4 to 5 hours, at a maximum of 3 doses, and

Group B was given cervical PGE2, $0.5 \mathrm{mg}$, gel, at a maximum of 3 doses and were re-assessed every 6 hours for the progress of labor.

Failure of induction was indicated by subjects not progressing into active labor within 12 hours of the initial dose and non-progressing after 12 hours in active labor.

The outcome indicators such as Induction to delivery interval, Incidence of vaginal delivery, Incidence of emergency LSCS and indications for LSCS were recorded in both Group A and Group B and analyzed.

Microsoft office excel 2013 and r software were used for statistical analysis.

\section{RESULTS}

The average age of the subjects included in the study was $25.3 \pm 5.22$.

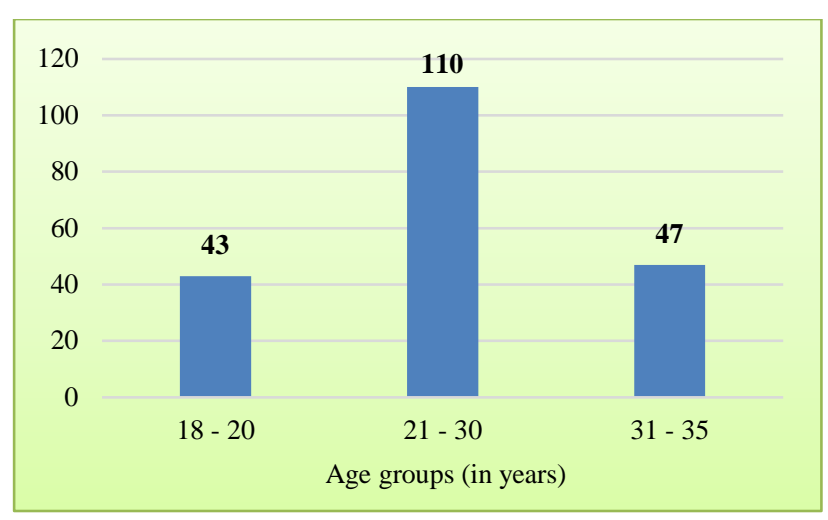

Figure 1: Age distribution.

The mean time taken from induction to vaginal delivery in Group A was $628 \pm 67$ minutes and in Group B was $839 \pm 118$ minutes.

The time taken from induction to delivery with Group A was shorter in comparison to Group B, with a ' $p$ ' value of 0.4 and the results were positively correlated with a ' $r$ ' value of 0.83 .

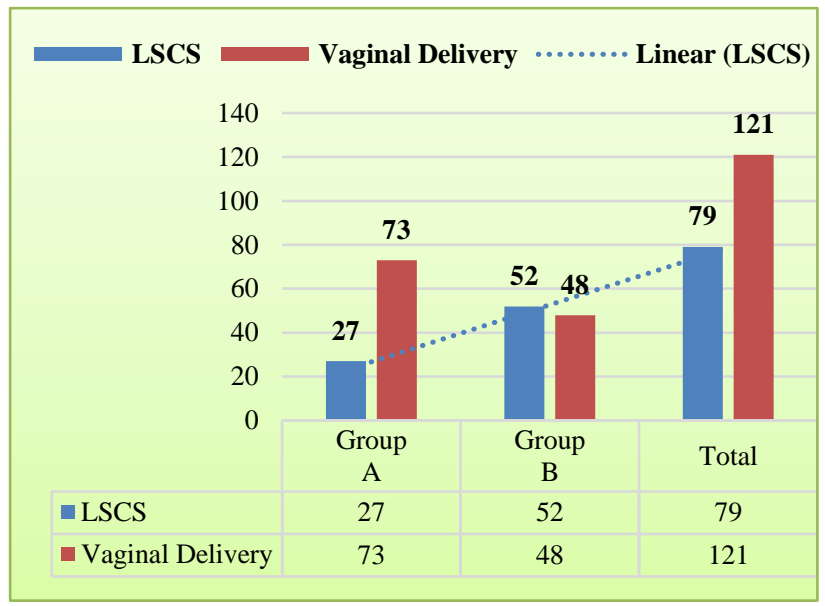

Figure 2: Incidence of vaginal deliveries and LSCS.

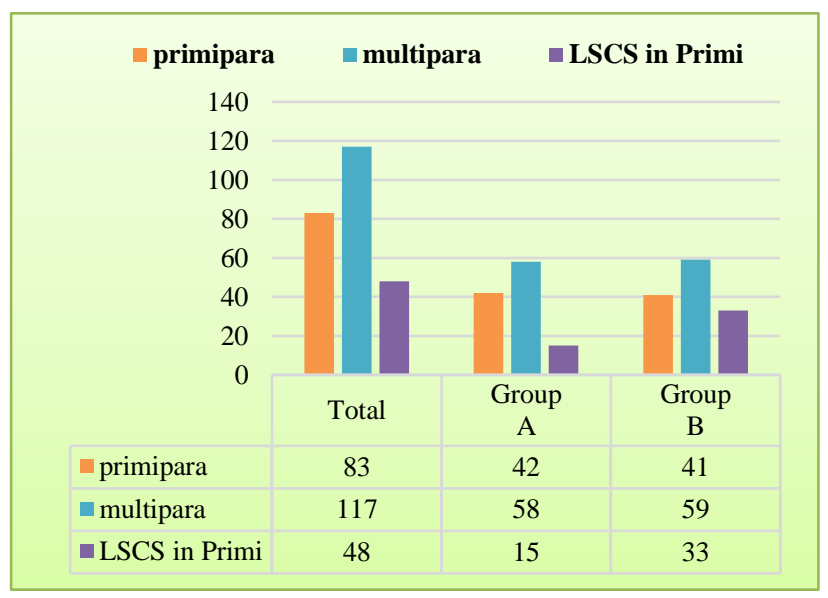

Figure 3: Incidence of LSCS in Primi's. 
Incidence of LSCS in Group B when compared to Group A, had a 'p' value of $<0.005$, which is statistically highly significant.

Incidence of LSCS in Primi's in Group B compared to Primi's in Group A was statistically significant with a 'p'value of 0.009 .

\section{Indications for LSCS}

The major indications for LSCS in both groups after induction were identified as

- NPL - Non progression of Labor (malposition's of vertex , cervical dystocia)

- $\quad$ F.D. - Fetal Distress (abnormal CTG patterns)

- MSL - Meconium Stained Liquor (grade 2, grade 3 with fetal distress)

- Miscellaneous (labor abnormalities).

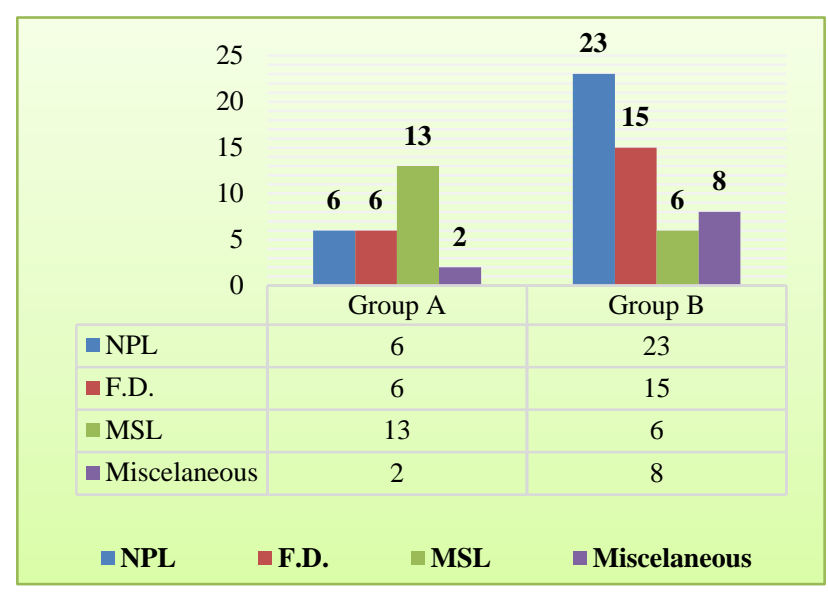

Figure 4: Indications of LSCS.

Meconium stained labor as an indication for LSCS in Group A had a ' $p$ ' value of $<0.1$ which is statistically significant

Non Progression of labor as an indication for LSCS in Group B had a 'p' value of $<0.001$ which is statistically highly significant

\section{DISCUSSION}

The average age group of the subjects selected for the current study was $25.3 \pm 5.22$. The majority of patients were in the age group of 20 to 30 . This was in concurrence with previous studies which have shown that women more than 35 years age had more incidence of antenatal and perinatal medical complications and were excluded as per our criteria..$^{7-9}$

The mean time taken from induction to vaginal delivery in Group A was $628 \pm 67$ minutes and in Group B was $839 \pm 118$ minutes. The time taken from induction to delivery with Group A was significantly shorter in comparison to Group B, with a ' $p$ ' value of 0.4 and the results were positively correlated with a ' $r$ ' value of 0.83 . This is in accordance with the previous studies which had similar results where induction to delivery time was shorter with misoprostol compared to dinoprostone. ${ }^{10,11}$

The PGE1 being an oral tablet, due to its better bio availability, can be a more effective agent for cervical ripening and uterine contractility for induction of labor compared to intra vaginal cervigel, the manual application of which might not deliver the desired amount of drug in the correct position.

In current study, we found that the Incidence of LSCS in Group B when compared to Group A was high with a 'p' value of $<0.005$, which is statistically highly significant. Our study observed that the incidence of LSCS in Primi's in both groups were generally high. These findings are in line with Khan NB et al who reported nulliparity to be a significant factor for failure of induction. ${ }^{12}$ Authors also observed that incidence of LSCS in Primi's in Group B compared to Primi's in Group A was higher with a 'p'value of 0.009 .

Non Progression of labor was observed to be the major indication for LSCS in Group B.

These results showing increased incidence of LSCS in Group B using intracervical PGE2 could be attributed to various labor specific abnormalities like persistent occipito-posterior position of vertex, cervical dystocia, and inappropriate instillation of intracervical gel.

Our findings regarding the increased incidence of LSCS with PGE2 in comparison with PGE 1, is in concurrence with the results of studies which found low-dose oral misoprostol as effective and safe as vaginal dinoprostone with significantly fewer women requiring caesarean delivery. ${ }^{13}$ Even the studies that used $50 \mathrm{mcg}$ oral misoprostol similar to present study, had lesser incidence of cesarean section. ${ }^{14}$

Meconium stained liquor was found to be the major indication for LSCS in Group A. This higher incidence might be in relation to the dose we used, i.e. $50 \mathrm{mcg}$ per oral instead of $25 \mathrm{mcg}$ per oral used in other studies which did not show any difference in fetal and maternal events. $^{11}$

The study has many limitations such as (i) the study does not consider the incidence and timing of augmentation of labor with oxytocin in the study groups (ii) PROM patients were excluded due to the contraindication to the use of intracervical PGE2, (iii) the study is confined to a specific age group which did not include elderly gravida's and pregnant women with associated medical co-morbidities.

The study hints towards the safety and efficacy of $50 \mathrm{mcg}$ misoprostol given orally for a maximum of 3 doses at an 
interval of 4 to 6 hours with proper monitoring of progress of labor leading to successful vaginal delivery with good neonatal outcomes in majority of cases.

The study concludes that using $50 \mathrm{mcg}$ oral misoprostol, is an effective and safe mode of induction of labor (in $>39$ weeks term pregnant women with Bishop's score <6) in comparison to PGE2 gel. The number of vaginal deliveries are more with the use of oral misoprostol and the induction to delivery interval is also lesser than that in intra-cervical PGE2 use.

Funding: No funding sources

Conflict of interest: None declared

Ethical approval: Not required

\section{REFERENCES}

1. Crane JM, Butler B, Young DC, Hannah ME. Misoprostol compared with prostaglandin E2 for labour induction in women at term with intact membranes and unfavourable cervix: A systematic review. BJOG. 2006;113(6):1366-76.

2. Lamichhane S, Subedi S, Banerjee B, Bhattara R. Outcome of induction of labor. A prospective study. Ann Int Med Dent Res. 2016;2(6):1-5.

3. Lawani OL, Onyebuchi AK, Iyoke CA, Okafo CN, Ajah LO. Obstetric outcome and significance of labour induction in a health resource poor setting. Obstet Gynecol Int. 2014;2014.

4. Donald I. Management of labour. 7th edition, New Delhi. BI publication Pvt Ltd. 2014;24.

5. Vrouenraets FP1, Roumen FJ, Dehing CJ, van den Akker ES, Aarts MJ, Scheve EJ. Bishop score and risk of cesarean delivery after induction of labor in nulliparous women. Obstet Gynecol. 2005 Apr;105(4):690-7.

6. Wing DA, Jones MM, Rahall A, Goodwin TM, Paul $\mathrm{RH}$; A comparison of misoprostol and prostaglandin
E2 gel for preinduction cervical ripening and labour induction. Am J Obstet Gynecol. 1995;172(6):18041810.

7. Jacobsson B, Ladfors L, Milsom I. Advanced maternal age and adverse perinatal outcome. Obstet Gynecol. 2004;104:727-33.

8. Joseph KS, Allen AC, Dodds L, Turner LA, Scott H, Liston R. The perinatal effects of delayed childbearing. Obstet Gynecol. 2005;105:1410-8.

9. Centre for Maternal and Child Enquiries (CMACE) perinatal mortality 2009: United Kingdom. London: CMACE, 2011.

10. Oza A, Shah JM, Mewada B, Thaker R. A comparative study between PGE1 and PGE2 for induction of labour in premature rupture of membrane at term. Int J Reprod Contracept Obstet Gynecol. 2016;5:202-5.

11. Raio L, Ghezzi F, Di Naro E, Brühwiler H, Lüscher KP. Shorter delivery time after induction with misoprostol. Zeitschrift fur Geburtshilfe und Neonatologie. 2001;205(4):147-51.

12. Khan NB, Ahmed I, Malik A, Sheikh L. Factors associated with failed induction of labour in a secondary care hospital. J Pak Med Assoc. 2012 Jan;62(1):6-10.

13. Kundodyiwa TW, Alfirevic Z, Weeks AD. Low-dose oral misoprostol for induction of labor: a systematic review. Obstet Gynecol. 2009;113:374-83.

14. Kwon JS, Davies GA, Mackenzie VP. A comparison of oral and vaginal misoprostol for induction of labour at term: a randomised trial. BJOG. $2001 \mathrm{Jan}$ $1 ; 108(1): 23-6$.

Cite this article as: Mukherjee $\mathrm{S}$, Valson $\mathrm{H}$, Balaji K. A study of effect of oral PGE1 and cervical PGE2 on induction of labor and mode of delivery. Int $\mathrm{J}$ Reprod Contracept Obstet Gynecol 2018;7:2160-3. 